that the phenols production from that plant had amounted to 850 tons.

As it is usually accepted that complete hydrogenation-reduction of phenols present in coal oils and coal derivatives leads to the ultimate production of hydrocarbons, it seems that the commercial hydrogenation of mixtures of coal and coal oils is incomplete and there naturally remains end-products still containing unconverted phenols. Every additional source of phenol production is of great national importance.

Our authority for the statement on octane ratings of 70 plus for the motor spirit produced by hydrogenation was Prof. W. A. Bone and A. N. Himus's most recent treatise on "Coal: its Constitution and Uses" (1936), p. 564, wherein the figure given for the No. 1 straight undoped spirit is 71-73. Aviation spirit was never under consideration in the article because, so far as octane rating is concerned, this is standardized at 87 , and every spirit must conform to it, whatever the method adopted to reach this rating.

The modifications to plant that have been necessary at Billingham to permit of the production of straight 75 octane No. 1 spirit were briefly referred to in the Company's annual report for 1937 .
11a Maresfield Gardens, Hampstead, N.W.3.
A. C. Cross.

JoHn L. Strevens.

\section{The Piltdown Bone Implement}

Mr. ReId MoIR ${ }^{1}$ mentions the theory that the bone implement from the Piltdown gravel was made by a rodent mammal, not by man. One of the finest examples of bone gnawed by rodents (presumably porcupines) is a fossil skull of the extinct panda, Aelureidopus baconi, which is exhibited in the British Museum (Natural History) not far from the implement. It is therefore easy to compare the work of rodents with that ascribed to man.

Hill-Place,

Arthor S. Woodward.

Hayward's Heath.

Sussex.

May 25.

I NaTURe, 141, 926 (May 21, 1938).

\section{Eggs of Stick Insects}

JUDGING by a recent correspondence in NATURE ${ }^{1}$, a number of readers are interested in rearing the common stick insect (Carausus). In any quantitative work on Carausus, it is a tedious operation to secure the eggs which are deposited among the debris of the breeding cage where, on account of their 'protective' devices, they may easily escape observation.

One of my students, Miss C. McK. Campbell, has devised a very easy method of securing the eggs, which may be of use to others. She plunges the whole of the floor contents of the breeding cage into a vessel containing water, stirs well, to break the surface film and so thoroughly wet each egg, and then allows the whole to settle. The eggs fall to the bottom, the debris floats. The supernatant material having been poured off the eggs can be carefully dried, counted and stored.

Sister Monica.

Notre Dame Training College Laboratory,

Dowanhill, Glasgow, W.2.

May 17.

${ }^{1}$ NATURE, 138, 886, 1058 (1936); 139, 156 (1937).
Stability of Intermetallic Compounds in the Molten State

THE atomic nature of solutions of cadmium in molten cadmium chloride (so-called 'pyrosols') was proved by an investigation of the partition co. efficient of cadmium between molten cadmium chloride and a molten metal phase, such as bismuth ${ }^{1}$.

The solutions of sodium in molten sodium halides (for example, sodium bromide or iodide) are being studied at present on similar lines by investigating the partition of sodium between molten sodium bromide and molten lead at $770^{\circ} \mathrm{C}$. in sealed tubes of Supremax glass. These systems also prove not to be colloidal. The partition curves reveal, however, the existence of strong interatomic forces in the metal phase which render a detailed analysis of the curves difficult.

A striking behaviour is observed when molten bismuth is used in the metal phase instead of lead. Bismuth, like lead, is not soluble in molten sodium bromide. However, when alloyed with sodium, considerable quantities of bismuth (up to several per cent) pass into the salt phase. Bismuth and sodium form compounds of considerable stability ${ }^{2}$, the maximum in the phase diagram being at $775^{\circ} \mathrm{C}$.* Obviously one of these compounds, presumably $\mathrm{Na}_{3} \mathrm{Bi}$, is soluble in the molten salt. A similar phenomenon is observed when a sodium alloy of antimony or tin is used as a liquid metal phase. The maxima in the phase diagrams of these metals with sodium are at $856^{\circ} \mathrm{C}$. and $580^{\circ}$. On the other hand, thallium, cadmium and lead do not pass into the salt phase when alloyed with sodium. These metals also form intermetallic compounds with sodium, but the maxima in the phase diagrams are at much lower temperatures ( $\mathrm{Na}-\mathrm{Tl}: 305^{\circ} \mathrm{C} ., \mathrm{Na}-\mathrm{Cd}: 385^{\circ} \mathrm{C}$., $\mathrm{Na}$ $\mathrm{Pb}: 405^{\circ}$ C.). Obviously these compounds are practically entirely decomposed at the temperature of our experiments, which is $350^{\circ}-450^{\circ}$ higher. The results obtained by the partition coefficient method therefore suggest that compounds of sodium with heavy metals may be stable at temperatures up to about $200^{\circ}$ above the melting temperature of the compound, but decompose at higher temperatures.

Chemistry Department,

University of Melbourne. E. HeYmanN. May 1.

* Only such compositions have been investigated in which the metal phase is liquid at $770^{\circ} \mathrm{C}$.

I Heymann, E., and Friedlaender, E., Z. physik. Chem., A, 148, 177 (1930). Farquharson, J., and Heymann, E., Trans. Farad. Soc., 31, 1004 (1935).

${ }^{2}$ Seith, W., and Kubaschewski, O., Z. Fiektrochem., 43, 743 (1937).

\section{Illusion of Convergent Beams of Light}

IN a recent letter ${ }^{1}$ under this title, Dr. A. H. Rosenthal describes an optical illusion produced by the rotating beam from a lighthouse. We studied this phenomenon last year ${ }^{2}$, and we think that both perspective and photometry are required for its explanation. Diffusion laws show that the brightness of the beam is great near the opposite horizon; this fact, together with the apparent convergence, gives to the observer a strong impression that the light. house is just beneath the horizon.
Ecole Polytechnique,
G. Colange.
Paris V.
Y. LE Grand.

May 16.

1 NATURe, 141, 836 (1938).

2 Colange and Le Grand, Comptes rendus, 204, 1882 (1937). 